\title{
Assessment of Pain Severity and Associated Factors of Post Operative Pain Among Adult Patients in Public Hospitals of Addis Ababa, Ethiopia, 2021
}

Abinet Besufekad ( $\square$ redietbeminet2017@gmail.com )

Kotebe Metropolitan University

Wosenyeleh Admasu

Addis Ababa University

Fissiha Fentie

Addis Ababa University

Sindew Mahmud

Kotebe Metropolitan University

Mulualem Setot

Addis Ababa University

Tewodrose Shitemaw

Kotebe Metropolitan University

\section{Research Article}

Keywords: pain severity, post operative pain, type of surgery, Ethiopia

Posted Date: December 16th, 2021

DOI: https://doi.org/10.21203/rs.3.rs-1131020/v1

License: (c) (i) This work is licensed under a Creative Commons Attribution 4.0 International License.

Read Full License 


\section{Abstract}

Background: Post-operative pain management is one of the key responsibilities of health professionals. Failure to manage post-operative pain effectively will lead to increase morbidity and mortality, long hospital stay, increase health care costs, and patient dissatisfaction. Despite improved understanding of pain mechanisms, advances in pain management approach, and other focused initiatives large proportion of post-operative patient's reports pain after surgery. Therefore the major aim of this study was to assess pain severity and associated factors among post-operative adult patients in public hospitals of Addis Ababa.

Methods and materials: A facility-based cross-sectional study was conducted. A total of 414 study participants were involved. Simple random sampling was used to select study participants. The data was collected by the standard questioner and checklist. The collected data were entered, cleaned, and analyzed by SPSS version 24.0 statistical software. Bi-variable analysis was employed to select independent predictors of pain severity and multivariable regression used to measure the association between independent and dependent variables. On bi-variable analysis, those variables with a value less than 0.20 were entered on multi-variable analysis. Finally, variables with a p-value $<0.05$ were declared as independent predictors of the outcome variables.

Results: A total of 406 study participants have responded to the interview giving a response rate of $98 \%$. The overall incidence of moderate to severe pain was $85.5 \%$. Preoperative analgesia adjusted odds ratio (confidence interval), 0.236(0.065-0.863), preoperative anxiety, 5.468(1.341-22.303), general surgery 7.627(1.901-30.602), orthopedics surgery, 7.195(1.055-49.094), size of the incision, 5.086(1.352-19.135), and postoperative analgesia; non-steroidal anti-inflammatory drugs 5.611(2.000-15.737), and tramadol, $4.714(1.506-14.753)$ was independent predictors of postoperative moderate to severe pain.

Conclusion: The study revealed that the overall incidence of postoperative pain was high in the study area. This reflects attention given to postoperative pain management is low. Preoperative analgesia, preoperative anxiety surgery type, incision length, and postoperative analgesia were independent predictors of postoperative pain.

\section{Introduction}

Pain is defined by the International Association for the Study of Pain (IASP) as "an unpleasant sensory and emotional experience associated with actual or potential tissue damage or described in terms of such damage" (1). It is one of the commonest medical and surgical complaints in all settings of healthcare services. Pain is identified by the World Health Organization (WHO) as a problem of global proportions (2). WHO and the International Association for the Study of Pain have recognized pain relief as a human right (3). Pain is a highly personal and subjective experience, which is increasingly recognized to be shaped by life events, mood, fear, anxiety, and anticipation among other influences (4). 
Controlling acute pain after surgery is important not only in the immediate postoperative phase but also to prevent chronic postsurgical pain, which can develop in as many as $10 \%$ of patients (4). Effective postoperative pain control is an essential component of the care of surgical patients. Advances in pharmacology, techniques, and education are making major inroads into the management of postoperative pain (5). Post-operation pain intensity is associated with variables like patient age, sex, type of surgery, anesthesia, duration of surgery and previous pain experience of the patient are some of the factors associated with moderate to severe postoperative pain development $(6,7)$.

For the effective and efficient management of postoperative pain health professional's required valid tools to assess pain to guide their pain management decisions (8). Its inadequate management will result in suffering, increased risk of morbidity and mortality, longer stay in hospital and higher cost, functional and quality-of-life impairment, delayed recovery time, prolonged duration of opioid use, and higher health care costs. In most developed and developing countries, postoperative pain is not adequately managed $(9,10)$. A postoperative patient who is experiencing pain cannot ambulate, therefore, may develop deep vein thrombosis. Again a patient who is experiencing chest pain may have suppressed of the cough reflex, therefore develop lung infection (11).

Despite improved understanding of pain mechanisms, increased awareness of the prevalence of postsurgical pain, advances in pain-management approaches, and other focused initiatives aimed at improving pain-related outcomes in recent decades, inadequately controlled postoperative pain continues to be a widespread, unresolved health care problem. Most surgical patients spend their immediate postoperative period in the PACU, where pain management, being unsatisfactory and requiring improvements, and affects further recovery.

In most developed and developing countries, postoperative pain is not adequately managed. In a resource-limited environment with an expected high incidence of postoperative pain, it is necessary to fully utilize basic analgesic modalities and to reserve more costly advanced methods for those who need it most. For this reason, the incidence and association factors of postoperative pain need to be identified. Therefore, this study aims to identify important evidence on exploring the incidence of moderate or severe pain and associated factors among surgically treated patients in government hospitals situated in Addis Ababa.

\section{Method And Materials}

\section{- Study design and Study period}

An Institutional Cross-sectional study design was employed. The study period was from February - April 2021. Administratively Addis Ababa is divided into 11 sub-cities and it has a total of 12 government hospitals and 96 health centers. Among the 12 public hospitals in Addis Ababa, three hospitals (Tikur Anbessa Specialized Hospital, Menelik II referral hospital, and Zeweditu Memorial Hospital) are selected by simple random sampling as a sampling unit. Ethical approval was obtained from the ethics review 
committee of Addis Ababa University. In addition, permission to conduct the research was obtained from the administrative office of the respective hospital. Before the data collection, verbal consent was obtained from each post-operation surgical patient. The study participants were informed about the purpose of the study, why and how they were select.

\section{- Source population and Study population}

All adult patients' undergone surgical procedures and admitted to the public hospitals of Addis Ababa. The study population was all adult patients' undergone major surgical procedures and admitted in the recovery room and surgical ward in the selected hospitals during the study period.

\section{- Sampling Method and procedure}

A simple random sampling method was used to select health facilities. First, the 12 public hospitals were listed. Finally, by simple random sampling, three hospitals were selected (Tikur Anbesa, Menelik II memorial, and Zeweditu memorial hospital) for the sampling unit. The calculated sample size was proportionally allocated to the selected hospital based on the previous three-month performance, which was 1217 (Tikur Anbesa 562, Menelik II memorial hospital 118 and Zewditu memorial hospital 105).

\section{- Eligibility criteria}

All adult surgical inpatients aged 18 years or older and who underwent major surgical procedures during the study period were included in the study. Patients with evidence of cognitive and mental illness, patients who are not admitted for recovery or direct transfer to an intensive care unit, cardiac surgery, cesarean section, patient refusal, patient continuous epidural analgesia, unconscious and emergency surgery during the data collection time were excluded from the study.

\section{- Sample size determination and procedure}

The sample size was determined using a single population proportion formula: $n=z a 2 / 2 p(1-p) / w 2$ plus $10 \%$ non-response rate

Where:

n=the final sample size

$\mathrm{Za} / 2=$ critical value for $95 \%$ confidence level which is equals to 1.96 ( $z$ value at $a=0.05$ )

$\mathrm{p}=$ proportion/prevalence

$\mathrm{W}=$ maximum allowable error in this cases $0.05(5 \%)$

Prevalence of moderate - severe of pain was taken from study done at Gonder $57 \%(6)$. 


\section{- Data collection tool and procedure}

Data was collected by the adopted standard questioner and checklist. The numeric rating scale was used to assess the level of pain. The numeric rating scale was translated into the Amharic language. The checklist was used to extract data on the type of surgery, anesthesia, a drug used for intraoperative and postoperative pain management, and duration of surgery and anesthesia from the patients' charts and anesthetic record sheets.

\section{- Data quality assurance}

To assure the data quality a one-day standardized training was given to three supervisors and six data collectors, who are health professionals working other than the recovery room. Appropriate information and instruction were given to the objective, relevance of the study, confidentiality of information, respondent's rights, informed consent, and technique of data collection. The pre-test was conducted in another hospital with $10 \%$ of the total sample size and the questions were checked for clarity, completeness, consistency, and questions that were created difficulty or unclear were rephrased and corrected. Some unnecessary questions were excluded and missing questions were incorporated. The quality of the data collected was checked on a daily basis by supervisors and the principal investigators.

\section{- Data analysis}

The collected data were entered, cleaned, and analyzed by SPSS version 24. Descriptive statistics like frequency distribution table, graph, and summary measures were computed. Furthermore, to identify a statistically significant association between the independent and dependent variable bi-variable and multivariable analyses were employed. To select independent predictors of pain controls, bi-variable logistic regression analysis was applied and multivariable regression was used to measure the association between independent and dependent variables. On a bi-variable analysis, those variables with a value less than 0.2 were entered on multivariable analysis. Finally, variables with p-value 0.05 were declared as independent predictors/ statistically significant / the outcome variables, and presented with $95 \% \mathrm{Cl}$ and AOR.

\section{- Operational definition}

Postoperative pain: the presence of pain in the postoperative period was defined as a patient as having pain and any pain score other than zero starting immediately after surgery and recovery room.

Numerical pain rating scale (NRS): is a valid method of pain assessment where patients are asked to score their pain ratings on a scale of $0-10$, corresponding to current, best, and worst pain experienced over the 12 hours (Fig 1)(12). 
Severe post-operative pain: a pain rating of 7-10 in 11 point numerical pain rating scale.

Moderate post-operative pain: a pain rating of 4-6 in 11 point numerical pain rating scale.

Mild post-operative pain: a pain rating of $1-3$ in 11 point numerical pain rating scale.

No pain: a pain rating of 0 (Zero) in 11 point numerical pain rating scale.

Moderate to severe pain: numeric rating score of moderate to severe post-operative pain.

Pain: patient having moderate or severe pain during the first $12 \mathrm{hrs}$ of post operative period.

\section{Results}

- Socio-demographics

From the total 414 , respondent 406 respondents complete the interview with a response rate of $98 \%$. The mean age of the participants was $43.72+/-15.76$ with the range of $18-86$ years; the majority of the respondents 237 (58.4\%) were found between the age range $18-45$ years. One hundred sixteen $(28.6 \%)$ of the respondents are completing college and above. Nearly half of the study participants were unemployed (Table 1).

Table-1 Socio-demographic characteristics of study participants who underwent surgical intervention in public Hospitals of Addis Ababa 2021 ( $(n=406)$ 


\begin{tabular}{|c|c|c|c|}
\hline Variables & Response & Frequency & Percent \\
\hline \multirow[t]{3}{*}{ Age } & 18- 45 years & 237 & 58.4 \\
\hline & $45-59$ years & 75 & 18.5 \\
\hline & $>=60$ years & 94 & 23.2 \\
\hline \multirow[t]{2}{*}{ Sex } & Male & 211 & 52 \\
\hline & Female & 195 & 48 \\
\hline \multirow[t]{5}{*}{ Educational status } & Can't read and write & 53 & 13.1 \\
\hline & Can read and write & 54 & 13.3 \\
\hline & Primary & 84 & 20.7 \\
\hline & Secondary & 99 & 24.4 \\
\hline & College and above & 116 & 28.6 \\
\hline \multirow[t]{3}{*}{ Marital status } & Married & 296 & 72.9 \\
\hline & Single & 85 & 20.9 \\
\hline & Divorced & 25 & 6.2 \\
\hline \multirow[t]{2}{*}{ Residence } & Urban & 275 & 67.7 \\
\hline & Rural & 131 & 32.3 \\
\hline \multirow[t]{4}{*}{ Occupational status } & Daily laborer & 38 & 9.4 \\
\hline & Farmer & 36 & 8.9 \\
\hline & Employed & 142 & 35 \\
\hline & Unemployed & 190 & 46.8 \\
\hline \multirow[t]{4}{*}{ Religion } & Orthodox Christian & 248 & 61.1 \\
\hline & Muslim & 87 & 21.4 \\
\hline & Protestant & 68 & 16.7 \\
\hline & Catholic & 3 & \\
\hline \multirow[t]{2}{*}{$\mathrm{BMI}^{\#}$} & $18.5-24.9$ & 346 & 85.2 \\
\hline & $>=25$ & 60 & 14.8 \\
\hline
\end{tabular}

${ }^{\#} B M I=$ Body Mass Index

- Pre-operative and patient related factors 
Of the total 406 study participants, $360(88.7 \%)$ of the participants has no history of surgery in the past month. The majority of the study participants (79.1\%) didn't take any pain medication in the preoperative periods. Of those who had a history of pain before surgery $60(76.9 \%)$ of them score their pain severity at a mild level. From 406 study participants, $57(14 \%)$ had chronic pain and $84(20.6 \%)$ had coexisting diseases before surgery (Table2).

Table-2: preoperative anesthesia and patient-related characteristics of the study participants who underwent surgical intervention in public hospitals of Addis Ababa 2021 ( $n=406)$

\begin{tabular}{|c|c|c|c|}
\hline Variable & Response & Frequency & Percent \\
\hline \multirow[t]{2}{*}{ Have you had surgery in the past month? } & Yes & 46 & 11.3 \\
\hline & No & 360 & 88.7 \\
\hline \multirow[t]{2}{*}{ Did you take pain medications in preoperative period? } & Yes & 84 & 20.7 \\
\hline & No & 322 & 79.1 \\
\hline \multirow{3}{*}{ ASA stage ${ }^{\#}$} & ASA I & 212 & 52.2 \\
\hline & ASAII & 121 & 29.8 \\
\hline & ASAIII & 73 & 18.0 \\
\hline \multirow[t]{2}{*}{ Did the patient was anxious during preoperative period } & Yes & 115 & 28.3 \\
\hline & No & 291 & 71.7 \\
\hline \multirow{2}{*}{$\begin{array}{l}\text { Did the patient had acute pain during preoperative } \\
\text { period }\end{array}$} & Yes & 78 & 19.2 \\
\hline & No & 328 & 80.8 \\
\hline \multirow{3}{*}{$\begin{array}{l}\text { If yes for the above question, how was the severity } \\
\mathrm{N}=78\end{array}$} & Mild & 60 & 76.9 \\
\hline & Moderate & 14 & 17.9 \\
\hline & Sever & 4 & \\
\hline \multirow[t]{2}{*}{ Do have previous chronic pain experience? } & Yes & 57 & 14 \\
\hline & No & 349 & 86 \\
\hline \multirow{4}{*}{$\begin{array}{l}\text { Did you receive information about pain treatment } \\
\text { options? } \\
\text { Did the patient have any coexisting disease? }\end{array}$} & Yes & 86 & 21.2 \\
\hline & No & 320 & 78.8 \\
\hline & Yes & 84 & 20.7 \\
\hline & No & 322 & 79.3 \\
\hline
\end{tabular}

${ }^{\#}$ ASA = American Society of Anesthesiology

- Intra operative anesthesia related factors

Of the total participants about two hundred fifty-six (63.1\%) participants, surgery was done with general anesthesia and almost one-third with spinal and nerve block, 17 (4.2\%) by a combination of general anesthesia and epidural (Fig 2).

For the study, participants participated in the study about $65.1 \%$ of participants were taken analgesics during induction of general anesthesia. Among the total patient $164(59.7 \%)$ induced by Theopentane and the majority of participants 207 (75.3\%) maintenances of anesthesia were maintained by Isoflurane (Table3). 
Table 3: intraoperative anesthesia-related characteristics of study participants who underwent surgical intervention in public hospitals of Addis Ababa 2021 ( $n=406)$

\begin{tabular}{|c|c|c|c|}
\hline Variable & Response & Frequency & Percent \\
\hline $\begin{array}{l}\text { Did the patient take analgesic during } \\
\text { induction? }\end{array}$ & $\begin{array}{l}\text { Yes } \\
\text { No }\end{array}$ & $\begin{array}{l}275 \\
131\end{array}$ & $\begin{array}{l}65.1 \\
34.9\end{array}$ \\
\hline $\begin{array}{l}\text { Type of drug for } \\
\text { induction }(n=275)\end{array}$ & $\begin{array}{l}\text { Propofol } \\
\text { Theopentane } \\
\text { Ketamine }\end{array}$ & $\begin{array}{l}82 \\
164 \\
5\end{array}$ & $\begin{array}{l}29.8 \\
59.7 \\
1.8\end{array}$ \\
\hline $\begin{array}{l}\text { Type of drug } \\
\text { Maintenance }(\mathrm{n}=275)\end{array}$ & $\begin{array}{l}\text { Ketamine and propofol } \\
\text { TIVA with Ketamine and } \\
\text { propofol } \\
\text { Halothane } \\
\text { Isoflurane }\end{array}$ & $\begin{array}{l}24 \\
10 \\
58 \\
207\end{array}$ & $\begin{array}{l}8.7 \\
3.6 \\
21.1 \\
75.3\end{array}$ \\
\hline $\begin{array}{l}\text { Did the patient take intraoperative } \\
\text { analgesic? }\end{array}$ & $\begin{array}{l}\text { Yes } \\
\text { No }\end{array}$ & $\begin{array}{l}276 \\
130\end{array}$ & $\begin{array}{l}68 \\
32\end{array}$ \\
\hline
\end{tabular}

Excluding analgesics given during induction of anesthesia, a total of 182 patients took additional analgesics during the intraoperative period and at the completion of the surgery. Among this $152(82.6 \%)$ patients were provided with analgesia at the intraoperative period and the remaining $30(17.4 \%)$ took analgesia at the completion of surgery. Of these patients, 53 (29\%) took diclofenac, 52 (28\%) morphine, and the least minority was given fentanyl (Fig 3 and Fig 4).

- Intra-operative surgical and post operative pain management related factors

From 406 participants 154 (37.9\%) undergone general surgery and the list majority 23 (5.7\%) were undergone Cardiothoracic surgery. The majority of surgical procedures were accomplished within 1-2 hrs $156(38.4 \%)$. One hundred eighty $(44.3 \%)$ of the surgical procedure were incision lengths of $5-10 \mathrm{~cm}$. And almost one-third of the participants $146(36 \%)$ was an interpretive blood loss of between $250-500 \mathrm{ml}$ (Table 4).

Table 4: Surgery and postoperative analgesia related characteristics of study participants who underwent surgical intervention in public hospitals of Addis Ababa 2021 ( $n=406)$ 


\begin{tabular}{|c|c|c|c|}
\hline Variables & Response & Frequency & Percent \\
\hline Type of surgery & $\begin{array}{l}\text { General } \\
\text { Urology } \\
\text { Gynecology } \\
\text { ENT } \\
\text { maxillofacial and } \\
\text { Orthopedics } \\
\text { Cardiothoracic } \\
\text { Neurology }\end{array}$ & $\begin{array}{l}154 \\
111 \\
20 \\
26 \\
47 \\
23 \\
25\end{array}$ & $\begin{array}{l}37.9 \\
27.3 \\
4.9 \\
6.4 \\
11.6 \\
5.7 \\
6.2\end{array}$ \\
\hline Incision length & $\begin{array}{l}<5 \mathrm{~cm} \\
5-10 \mathrm{~cm} \\
>10 \mathrm{~cm}\end{array}$ & $\begin{array}{l}53 \\
180 \\
173\end{array}$ & $\begin{array}{l}13.1 \\
44.3 \\
42.6\end{array}$ \\
\hline Duration of anesthesia & $\begin{array}{l}<1 \text { hrs } \\
1-2 \text { hours } \\
2-3 \text { hours } \\
>3 \text { hours }\end{array}$ & $\begin{array}{l}60 \\
156 \\
96 \\
94\end{array}$ & $\begin{array}{l}14.8 \\
38.4 \\
23.6 \\
23.2\end{array}$ \\
\hline Duration of surgery & $\begin{array}{l}<1 \text { hrs } \\
1-2 \text { hours } \\
2-3 \text { hours } \\
>3 \text { hours }\end{array}$ & $\begin{array}{l}75 \\
162 \\
87 \\
82\end{array}$ & $\begin{array}{l}18.5 \\
39.9 \\
21.4 \\
20.2\end{array}$ \\
\hline Estimated intraoperative blood loss & $\begin{array}{l}<100 \mathrm{ml} \\
100-250 \mathrm{ml} \\
250-500 \mathrm{ml} \\
500-1000 \mathrm{ml} \\
>1000 \mathrm{ml}\end{array}$ & $\begin{array}{l}66 \\
105 \\
146 \\
77 \\
12\end{array}$ & $\begin{array}{l}16.3 \\
25.9 \\
36.0 \\
19.0 \\
3\end{array}$ \\
\hline Type of postoperative pain management & $\begin{array}{l}\text { Nerve block } \\
\text { Systemic opioids } \\
\text { NSAID } \quad \text { without } \\
\text { opioids } \\
\text { Tramadol }\end{array}$ & $\begin{array}{l}106 \\
28 \\
182 \\
90\end{array}$ & $\begin{array}{l}26.1 \\
6.9 \\
44.8 \\
22.2\end{array}$ \\
\hline $\begin{array}{l}\text { Drugs given in the recovery room to relive } \\
\text { pain }\end{array}$ & $\begin{array}{l}\text { Pethidine } \\
\text { Morphine } \\
\text { Diclofenac } \\
\text { Tramadol } \\
\text { Epidural Anesthesia } \\
\text { Nerve block }\end{array}$ & $\begin{array}{l}2 \\
4 \\
62 \\
73 \\
9 \\
4\end{array}$ & $\begin{array}{l}1.3 \\
2.6 \\
40.2 \\
47.4 \\
5.8 \\
2.6\end{array}$ \\
\hline Was any pain documented & $\begin{array}{l}\text { Yes } \\
\text { No }\end{array}$ & $\begin{array}{l}25 \\
381\end{array}$ & $\begin{array}{l}6.2 \\
93.8\end{array}$ \\
\hline
\end{tabular}

- Over all moderate to severe pain Prevalence

The overall prevalence of moderate to severe pain within the first 12 hours of the postoperative period between the total participants 347 (85.5\%, $(\mathrm{Cl}=81.8-88.9))$ and no pain to mild pain were $59(14.5 \%)$. $(\mathrm{Fig}$ 5.6)

- Factors affecting severity of pain among post operative patients

Preoperative analgesia was significantly associated with the severity of postoperative pain. Patients who didn't take preoperative analgesia were $74.6 \%$ more likely to develop postoperative pain compared to 
those who took $(0.236(0.065-0.863)$. Preoperative anxiety was significantly associated with the severity of pain. Patients who experience preoperative anxiety were 5.468 times more likely to develop moderate to severe pain compared with those who didn't experience it (5.468(1.341-22.303). The type of surgery was statically significant with moderate to severe postoperative pain. Patients with general and orthopedics surgeries were 5.855 and 6.482 times more likely to develop moderate to severe postoperative pain compared with neurological surgery (5.855(1.601-21.418), (6.482(1.055-49.094)) respectively.

Length of incision was significantly associated with postoperative pain. Patients with incision size greater than $10 \mathrm{~cm}$ were 4.788 times more likely to develop moderate to severe pain compared with incision length less than $5 \mathrm{~cm}$ (4.788 (1.322-17.348). Patients whose pain was managed with NSAID and tramadol were 4.577 and 3.323 times more likely to develop moderate to severe postoperative pain compared with those whose pain was managed with a nerve block (4.577(1.764-11.876), 3.323(1.1879.301) respectively (Table 5).

Table 5: independent variables associated with pain severity (moderate to severe pain) in study participants underwent surgical intervention in public Hospitals of Addis Ababa 2021 (n=406) 


\begin{tabular}{|c|c|c|c|c|c|}
\hline \multirow[t]{2}{*}{ Variables } & \multicolumn{2}{|c|}{ Pain severity } & \multirow[b]{2}{*}{$\begin{array}{l}\text { COR }^{\# \# \#} \\
\left(95 \% \mathrm{Cl}^{\# \#}\right)\end{array}$} & \multirow[b]{2}{*}{$(95 \% \mathrm{Cl})$} & \multirow[b]{2}{*}{ P-value } \\
\hline & $\begin{array}{l}\text { No-mild } \\
\text { pain }\end{array}$ & $\begin{array}{l}\text { Moderate - } \\
\text { severe pain }\end{array}$ & & & \\
\hline \multicolumn{6}{|c|}{ Did the patient take preoperative analgesia } \\
\hline Yes & $5(5.9)$ & $80(94.1)$ & 1 & 1 & \\
\hline No & $54(16.8)$ & 267(83.2) & $\begin{array}{l}0.309(0.120- \\
0.799)\end{array}$ & $\begin{array}{l}0.236(0.065- \\
0.863)\end{array}$ & $0.029 * \star$ \\
\hline \multicolumn{6}{|c|}{ Patient preoperative anxiety } \\
\hline Yes & $4(3.5)$ & $111(96.5)$ & $\begin{array}{l}6.467(2.286- \\
18.293)\end{array}$ & $\begin{array}{l}5.468(1.341- \\
22.303)\end{array}$ & $0.018^{\star *}$ \\
\hline No & $55(18.9)$ & 236(81.1) & 1 & 1 & \\
\hline \multicolumn{6}{|l|}{ Type of surgery } \\
\hline General & 16(10.4) & 138(89.6) & $\begin{array}{l}3.354(1.216- \\
9.255)\end{array}$ & $\begin{array}{l}7.627(1.901- \\
30.602)\end{array}$ & $0.004^{\star *}$ \\
\hline Urology & 13(11.7) & $98(83.3)$ & $\begin{array}{l}2.932(1.029- \\
8.355)\end{array}$ & $\begin{array}{l}3.705(0.685- \\
20.046)\end{array}$ & 0.128 \\
\hline Gynecology & $2(10)$ & 18(90) & $\begin{array}{l}3.500(0.638- \\
19.195)\end{array}$ & $\begin{array}{l}3.895(.388- \\
39.065)\end{array}$ & 0.248 \\
\hline $\begin{array}{l}\text { ENT and } \\
\text { Maxillofacial }\end{array}$ & 12(46.2) & 14(53.8) & $\begin{array}{l}0.454(0.142- \\
1.454)\end{array}$ & $\begin{array}{l}0.646(0.149- \\
2.790)\end{array}$ & 0.558 \\
\hline Orthopedics & $8(17)$ & $39(83)$ & $\begin{array}{l}1.896(0.596- \\
6.035)\end{array}$ & $\begin{array}{l}7.195(1.055- \\
49.094)\end{array}$ & $0.044^{\star *}$ \\
\hline Cardiothoracic & $1(4.3)$ & 22(95.7) & $\begin{array}{l}8.556(0.961- \\
76.135)\end{array}$ & $\begin{array}{l}11.902(0.660- \\
214.53)\end{array}$ & 0.093 \\
\hline Neurology & $7(28)$ & 18(72) & 1 & 1 & \\
\hline \multicolumn{6}{|l|}{ Incision length } \\
\hline$<5 \mathrm{~cm}$ & $12(22.6)$ & $41(77.4)$ & 1 & 1 & \\
\hline $\begin{array}{l}\text { Incision length 5- } \\
10\end{array}$ & $40(22.2)$ & $140(77.8)$ & $\begin{array}{l}1.024(0.492- \\
2.132)\end{array}$ & $\begin{array}{l}1.162(0.418- \\
3.229)\end{array}$ & 0.773 \\
\hline $\begin{array}{l}\text { Incision length > } \\
10 \mathrm{~cm}\end{array}$ & $7(4)$ & 166(96) & $\begin{array}{l}6.941(2.572- \\
18.732)\end{array}$ & $\begin{array}{l}5.086(1.352- \\
19.135)\end{array}$ & $0.016^{\star \star}$ \\
\hline \multicolumn{6}{|c|}{ Post operative pain management } \\
\hline Nerve block & 17(16.2) & $88(83.8)$ & 1 & 1 & \\
\hline Systemic opioid & $6(21.4)$ & $22(78.6)$ & $\begin{array}{l}0.708(0.250- \\
2.007)\end{array}$ & $\begin{array}{l}3.504(0.803- \\
15.290)\end{array}$ & 0.095 \\
\hline
\end{tabular}




\begin{tabular}{|c|c|c|c|c|c|}
\hline NSAIDs & 22(12) & 161(88) & $\begin{array}{l}1.414(0.713- \\
2.802)\end{array}$ & $\begin{array}{l}5.611(2.000- \\
15.737)\end{array}$ & $0.001^{\star *}$ \\
\hline Tramadol & $14(15.6)$ & $76(84.4)$ & $\begin{array}{l}1.049(0.485- \\
2.267)\end{array}$ & $\begin{array}{l}4.714(1.506- \\
14.753)\end{array}$ & $0.008^{\star \star *}$ \\
\hline
\end{tabular}

${ }^{\#}$ AOR=adjusted odds ratio, ${ }^{\# \# C l=c o n f i d e n c e ~ i n t e r v a l, ~}{ }^{\# \#} \mathrm{COR}=$ crude odds ratio

** =statistically significant.

\section{Discussion}

The study revealed that an overall prevalence of moderate to severe pain was $85.5 \%$ in the first 12 hours of the postoperative period. Preoperative analgesia, Preoperative anxiety, types of surgery, incision size greater than $10 \mathrm{~cm}$, and post-operative pain was management was independent predictors of moderate to severe postoperative pain.

The Prevalence of postoperative moderate to severe pain was found to be $85.5 \%$. This reflects that there was poor postoperative pain management. But, it is comparable with other studies done in Jimma $88.2 \%$, Tanzania $85.5 \%$, and Nigeria $79.6 \%(11,13,14)$, and higher than the studies conducted in Gondar $57 \%$ postoperative pain at recovery stage (6). This lower prevalence from Gondar can be explained as the reported incidence only included patients in the recovery room (within $2 \mathrm{hr}$ of post-surgery) and our study reported an overall pain severity in the first 12 hours.

Similarly, our study result was higher than the studies conducted in Singapore (32.2\%), Eastern Poland (59\%), Dutch (41\%), South Africa $62 \%$, and Mekelle (30.5\%), $(7,9,15-18)$. This variation may be due to differences in infrastructure, a postoperative pain management protocol, sample size, and pain assessment time. In our study, most of the patient was interviewed in the first 12 hours after surgery but other includes up to four days after surgery. The finding of the study was also lower than the study conducted in Tanzania (95.6\%) (19). This variation may be due to different types of surgery in which the study includes only orthopedics and general surgery but ours include other types of surgery.

Evidence from our study revealed that preoperative analgesia was protective from moderate to severe postoperative pain. This is supported by the study conducted in Serbia (20). This can be explained as the pathophysiology of surgical pain which includes peripheral and central sensitization. Peripheral sensitization occurs when inflammatory mediators released at the wound site decrease the threshold of terminal nerve endings, leading to nociceptive pain. On the other hand, central sensitization results from an enhanced response that is provoked by hyperexcitability of the neurons in the dorsal horn of the spinal cord secondary to intense afferent impulses originated in the site of injury $(21,22)$. Peripheral and central sensitizations are manifested clinically as increased sensitivity to pain at the site of injury or inflammation. Central and peripheral sensitizations are the major causes of hypersensitivity to pain after an injury. Therefore blocking or interruption of the surgical noxious impulses should reduce the 
amplification of the nociceptive signals, making the timing of analgesic administration an important aspect of pain management $(23,24)$.

Preoperative anxiety was found to be significantly associated with postoperative pain. This result is supported in the study done in Serbia (20), Turkey (25). This could be explained as anxiety is characterized by distress, fear, and activation of the autonomic nervous system; thus it is associated with the same Psychophysiological response as acute pain (25).

Patients with general and orthopedic surgery were associated with moderate to severe postoperative pain. This result is supported by a study done in Cape Town which reported a higher incidence of severe postoperative pain after orthopedic surgery (36). Another study done in Singapore showed a higher incidence of pain after orthopedic and general surgery (7). In addition, a study done in the Netherlands showed orthopedics and general surgery were significantly associated with moderate to severe postoperative pain (18).

Patient with incision size greater than $10 \mathrm{~cm}$ was associated to moderate to severe postoperative pain. This is supported by the studies conducted in Gonder (6). This is supported by the fact that larger incision size will increase actual tissue damage increase pain.

Type of postoperative analgesia has a significant association with moderate to severe pain in postoperative pain. Patients whose pain was managed by NSAID and tramadol only reported more moderate to severe pain compared with those managed with a nerve block and systemic opioids plus NSAIDs/Tramadol. This result is supported by a study in Jimma that reveals patients whose pain was managed by NSAID and tramadol only reported more moderate to severe postoperative pain (13). This report could be explained that the application of multimodal analgesia techniques as the standard method for the prevention of pain in surgery is one alternative to improve the recovery process.

The independent variables were significant in other studies such as the type of anesthesia, sex. Age, marital status, educational status, ASA, BMI, co-existing disease, preoperative acute and chronic pain, and duration of surgery were not significant in this study found. This may be due to differences in sample size, time of pain assessment, study area, study time, and type of surgery in this study. The limitation of this study includes the study is cross-sectional, it doesn't show the cause and effect relationship.

\section{Conclusion}

Evidence from the study revealed that the overall prevalence of postoperative pain was high in the study area. This reflects attention given to postoperative pain management is low. It is also revealed that preoperative analgesia was negatively associated with post-operative moderate to severe pain, whereas preoperative anxiety, type of surgery, incision size, and postoperative analgesia had a positive association with moderate to severe postoperative pain.

\section{Declarations}


Ethics approval and consent to participate: After the purpose, importance and risk of the study were explained, written informed consent was obtained from each participant. Participants were informed that they can withdraw from the study without any restriction at any time.

Consent for publication: The author declares that any person named as co-author of the contribution is aware of the fact and has agreed to be so named. The Authors guarantee that the Work has not been previously published elsewhere.

Competing interests: The authors have no conflicts of interest to declare.

Availability of data and material: The data used in this study were collected by trained data collectors and authors are willing to share the data upon request from peer researchers. The protocol and consent form is presented as an additional file attachment.

Funding: This work was funded by Addis Ababa University.

Author contribution: Authors will take public responsibility for the contents, have contributed substantially to the drafting, and have approved the final version.

- Abinet Besufekad ${ }^{1}$ (M.Sc.): This author helped on substantial intellectual contributions to conception, design, and acquisition of data, analysis, and interpretation of data as well as on preparing the manuscript for this study.

- Wosenyeleh Admasu² (Assistant professor.): have made substantial contributions to the conception, design, and acquisition of data, analysis, and interpretation of data as well as on preparing the manuscript for this study.

- Fissiha Fentie ${ }^{3}$ (M.Sc): have made substantial contributions to the conception, design, and acquisition of data, analysis, and interpretation of data as well as on preparing the manuscript for this study.

- Mulualem Setot ${ }^{3}$ (M.Sc.): have made substantial contributions to the conception, design, and acquisition of data, analysis, and interpretation of data as well as on preparing the manuscript for this study.

- Sindew Muhammed ${ }^{3}$ (M.Sc): has been involved in analysis, interpretation of data and drafting the manuscript, and revising it critically for important intellectual contents.

- Tewodrose Shitemaw:- has been involved in analysis, interpretation of data and drafting the manuscript, and revising it critically for important intellectual contents.

\section{Acknowledgements}

We would like to thank Addis Ababa University, College of Medicine and Health Science for funding this research. Our gratitude goes to supervisors, data collectors, and study respondents. Finally, we would like to thank all those, who in one way or another have contributed to this work. 


\section{Abbreviations}

ASA - American Society of Anesthesiologists, Cl - Confidence Interval, GA - General Anesthesia, NRSNumerical Rating Scale, PACU - Post Anesthesia Care Unit, SPSS- Statistical Package for Social Sciences, BMI-Body Mass Index, AOR-Adjusted Odds Ratio, COR-Crude Odds Ratio, NSAID- Non-steroidal Anti-Inflammatory Drugs, IASP- International Association for the Study of Pain.

\section{References}

1. Treede RD. The International Association for the Study of Pain definition of pain: As valid in 2018 as in 1979, but in need of regularly updated footnotes. Pain Reports. 2018;3(2):1-3.

2. Gureje O, Von Korff M, Simon GE, Gater R. Persistent pain and well-being: A World Health Organization study in primary care. J Am Med Assoc. 1998;280(2):147-51.

3. Brennan F, Carr DB, Cousins M. Pain management: A fundamental human right. Anesth Analg. 2007;105(1):205-21.

4. The Lancet. Best practice in managing postoperative pain. Lancet [Internet]. 2019;393(10180):1478. Available from: http://dx.doi.org/10.1016/S0140-6736(19)30813-X

5. Peccora C, Zhou J. Postoperative acute pain management. Essent Clin Anesth Rev Keywords, Quest Answers Boards. 2015;75246:448-52.

6. Admassu WS, Hailekiros AG, Abdissa ZD. Severity and Risk Factors of Post-Operative Pain in University of Gondar Hospital, Northeast Ethiopa. J Anesth Clin Res. 2016;7(10).

7. Chan JJI, Thong SY, Tan MGE. Factors affecting postoperative pain and delay in discharge from the post-anaesthesia care unit: A descriptive correlational study. Proc Singapore Healthc. 2018;27(2):118-24.

8. Aziato L, Dedey F, Marfo K, Asamani JA, Clegg-Lamptey JNA. Validation of three pain scales among adult postoperative patients in Ghana. BMC Nurs [Internet]. 2015;14(1):1-9. Available from: http://dx.doi.org/10.1186/s12912-015-0094-6

9. Shanmugam R, Abrha K, Tsegay A, Shumbahri A, Asir AM, Yemane A, et al. Assessment of Postoperative Pain Management in Mekelle Public Hospitals, Ethiopia. Int J Dev Res [Internet]. 2018;08(10):23843-9. Available from: http://www.journalijdr.com

10. Gan TJ. Poorly controlled postoperative pain: Prevalence, consequences, and prevention. J Pain Res. 2017;10:2287-98.

11. Herbert $\mathrm{M}$, Kondo $\mathrm{C}$. Postoperative pain management outcomes among adults treated at a tertiary hospital in Moshi , Tanzania. Tanzan J Health Res. 2014;16(1). 
13. Woldehaimanot TE, Eshetie TC, Kerie MW. Postoperative pain management among surgically treated patients in an Ethiopian hospital. PLoS One. 2014;9(7):1-9.

14. Brennan F, Carr DB, Cousins M, Treede RD, Gureje O, Von Korff M, et al. Incidence, patient satisfaction, and perceptions of post-surgical pain: Results from a US national survey. Tanzan J Health Res [Internet]. 2018;16(1):1-9. Available from: https://doi.org/10.1016/j.bja.2017.11.098

15. Sommer M, De Rijke JM, Van Kleef M, Kessels AGH, Peters ML, Geurts JWJM, et al. Issn: 22309926 Original Research Article Open Access Assessment of Postoperative Pain Management in Mekelle Public Hospitals , Ethiopia. Eur J Anaesthesiol. 2018;25(2):118-24.

16. Borys M, Zyzak K, Hanych A, Domagała M, Gałkin P, Gałaszkiewicz K, et al. Survey of postoperative pain control in different types of hospitals: A multicenter observational study. BMC Anesthesiol. 2018;18(1):1-9.

17. Murray AA, Retief FW. Acute postoperative pain in 1231 patients at a developing country referral hospital: Incidence and risk factors. South African J Anaesth Analg. 2016;22(1):26-31.

18. Sommer M, De Rijke JM, Van Kleef M, Kessels AGH, Peters ML, Geurts JWJM, et al. The prevalence of postoperative pain in a sample of 1490 surgical inpatients. Eur J Anaesthesiol. 2008;25(4):267-74.

19. Mwashambwa MY, Yongolo IM, Kapalata SN, Meremo AJ. Post-operative pain prevalence, predictors, management practices and satisfaction among operated cases at a regional referral hospital in Dar es Salaam, Tanzania. Tanzan J Health Res. 2018;20(2):1-8.

20. Mimic A, Bantel C, Jovicic J, Mimic B, Kisic-Tepavcevic D, Durutovic O, et al. Psychological factors as predictors of early postoperative pain after open nephrectomy. J Pain Res. 2018;11:955-66.

21. Woolf CJ. J pain NIH Public Access. 2012;152:1-31.

22. Woolf CJ. Review Pain: Moving from Symptom Control toward Mechanism-Specific. 2004;44151.

23. Miura M, Sasaki M, Mizukoshi K, Shibasaki M, Izumi Y, Shimosato G. Peripheral sensitization caused by insulin-like growth factor 1 contributes to pain hypersensitivity after tissue injury. Pain [Internet]. 2011;152(4):888-95. Available from: http://dx.doi.org/10.1016/j.pain.2011.01.004

24. Latremoliere and Woolf, Plasticity CN. NIH Public Access. J pain. 2010;10(9):895-926.

25. Ocalan R, Akin C, Disli ZK, Kilinc T, Ozlugedik S. Preoperative anxiety and postoperative pain in patients undergoing septoplasty. B-ENT. 2015;11(1):19-23. 
Figures

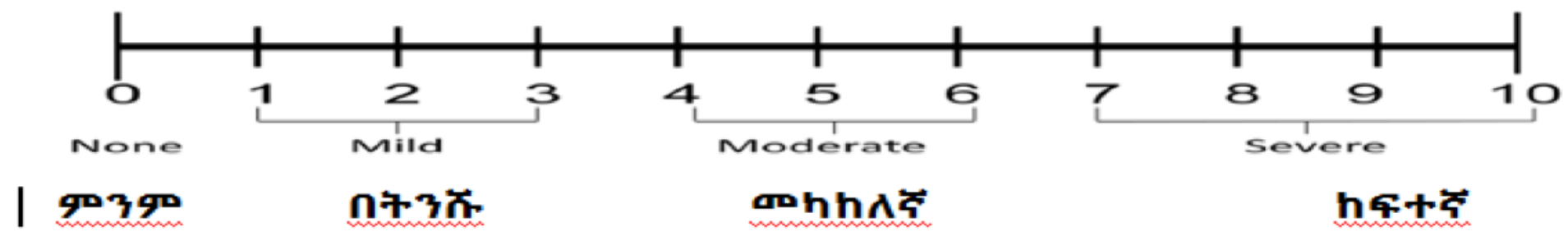

Figure 1

$<p>$ The Numeric Rating Scale (NRS) $</ p>$

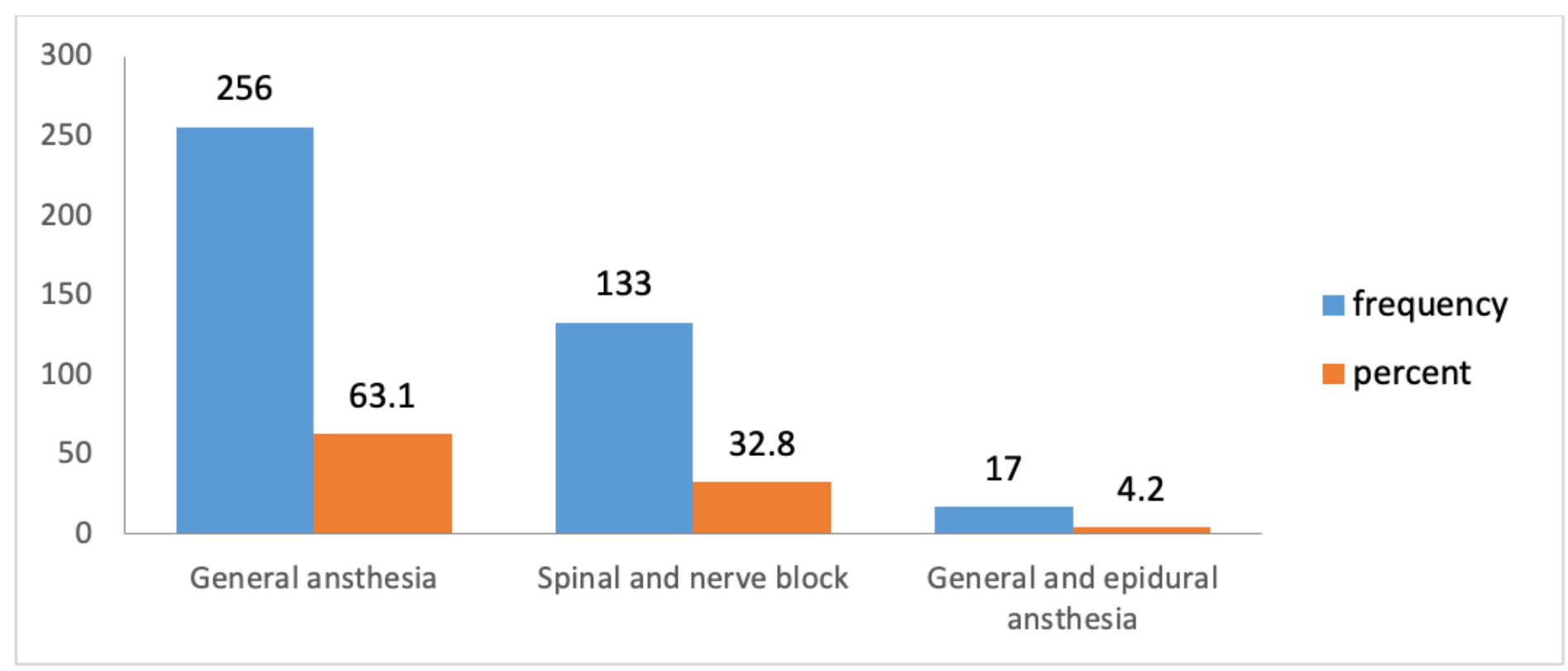

Figure 2

$<p><$ em $>$ Types of anesthesia given for the study participants who underwent surgical intervention in public hospitals of Addis Ababa $2021(n=406)</ e m></ p>$

Figure 3

$<\mathrm{p}><\mathrm{em}>$ Type of intraoperative analgesia used among post-operative surgical patients in public hospitals of Addis Ababa 2021 ( $n=182)</ e m></ p>$

Figure 4 
$<p><e m>$ Time at intraoperative analgesia given among post-operative surgical patients in public hospitals of Addis Ababa $2021(\mathrm{n}=182)</ e m></ p>$

\section{Figure 5}

$<p><$ em $>$ \&nbsp;Overall pain severity among postoperative adult patients in public hospitals of Addis Ababa $2021</$ em $></$ p $>$ 